\title{
Can 100 Students Debate One Another? Adapting the Nuclear Proliferation Debate for a Large Lecture Class
}

\author{
Adam Irish \\ California State University, Chico \\ Levi Watts \\ California State University, Chico
}

Often professors teaching in large lecture halls are often unwillingly cast into the role of sage on the stage. This article takes an active learning seminar teaching method - the structured classroom debate - and adapts it to a large lecture hall class. Beyond describing how we conducted a simultaneous lecture hallsized debate, we offer evidence that debate participants displayed improved recall of the facts and positions in the scholarly debate about the danger of nuclear proliferation. We also review the debate notes to explore how students held or shifted positions during the large classroom debate. With thoughtful updates and alterations, other active learning techniques can and should be brought out of the seminar room and into the lecture hall.

Keywords: debate, lecture, nuclear, large class, active learning

\section{INTRODUCTION}

Every year, in late October, students at Chico State enrolled in Introduction to International Relations (IR) find themselves immersed in a debate. The question on offer - given the logic of deterrence, is nuclear proliferation dangerous? Scholars familiar with research on nuclear proliferation will know that this debate was famously contested, across articles, books, and public appearances, between Kenneth Waltz and Scott Sagan (2012). Waltz and Sagan's scholarship provides the basis for the debate reviewed in this article (Rublee, 2007).

Before the debate, students read a chapter from Waltz and Sagan's co-authored book on nuclear proliferation and watched a video of Waltz and Sagan debating (www.uctv.tv/shows/Scott-Sagan-andKenneth-Waltz-The-Spread-of-Nuclear-Weapons-A-Debate-Renewed-9491). We use blackboard tracking software to ensure that each student accessed these materials, though we cannot know the effort they put into their subsequent studying. Then, on the appointed day, for seventy-five minutes, students recreate, reframe, and wrestle with arguments about the dangers of nuclear proliferation. They examine core concepts like rationality, deterrence, leadership, uncertainty, and organizational theory, to name a few. None of this is notably different from debates in other classes across campus, except that - in most semesters - this Introduction to IR debate plays out among over 100 students all at once.

This article focuses on scaling up the seminar teaching method of a structured debate (Hensley \& Oakley, 1998; Omelicheva, 2007; Oros, 2007) to work in a large lecture hall class. We also provide some 
preliminary evidence that even operating at very large scale is it possible for this active learning technique to aid student learning.

Bromley (2013) and Bain (2004) both remind us that there are a variety of ways for students to learn and that we are well-advised to seek out engaging teaching methods. In that spirit, this essay recounts how we adapted a seminar-sized structured debate to fill a lecture hall. Though class debates and their active learning cousins, simulations and moot courts, have been examined in a variety of articles with at times mixed results (Baumgartner \& Morris, 2015; Omelicheva \& Avdeyeva, 2008; Raymond \& Usherwood, 2013). Our specific teaching innovation of an entire lecture hall of students participating in a debate simultaneously remains, to the best of our knowledge, unexamined.

Drawing evidence from the Introduction to IR debate in Fall 2017, we explore debating writ large. Irish was the instructor of record for this course and Watts assisted on both this and another teaching experiment during Fall 2017. By laying bare how we adapted structured classroom debates to the lecture hall and providing an initial set of data, we hope to inspire other scholars to adapt other seminar-sized techniques to their large courses. A variety of activities such as poster presentations, student led discussions, and full class simulations, all seem ripe to be adapted.

To investigate the effects of conducting a simultaneous lecture hall debate, we review two artifacts: 1) the debate notes from the 81 students that participated in the debate and 2) follow up quiz scores from 103 students, 74 of which participated in the debate and 29 that did not. The debate notes document each student's arguments and rebuttals, providing a window into student thinking about nuclear proliferation. From the combination of quiz scores and debate notes, we draw conclusions about both the learning effects of participating in such a large debate as well as the students' positions and the arguments they found compelling.

\section{Verbal Prizefighting No Longer}

Great debates are typically framed as prizefights: two contenders enter into a discourse, exploring lines of argument, hunting for a weak spot in the other side's reasoning, and verbally sparing to highlight disagreements and enliven the event for spectators or to sway judges (Baumgartner \& Morris, 2015). The Lincoln-Douglas debates over slavery, Richard Dawkins and John Lennox arguing about intelligent design, and nearly every criminal trail are all exemplars of the debate-prize fight metaphor in action. One issue is considered, time for arguments and rebuttals is allotted, and each side fights to persuade the audience of the correctness its position.

The advantages of prizefight debates in a seminar classroom are several. They clarify positions, finetune arguments, motivate further investigation of crucial evidence or cases, practice public speaking, and increase in student achievement (Omelicheva \& Avdeyeva, 2008, p. 604; Oros, 2007, p. 303). One critical weakness of structured classroom debates is that - outside of those students engaged in the debate - the majority are consigned to role of spectator or judge (Farrelly, 2013).

A small seminar class overcomes this obstacle with a class Q\&A and debriefing (Raymond \& Usherwood, 2013, p. 163). Because student observers are able to voice their ideas during a Q\&A session or when debriefing the debate their temporary exclusion from the debate proper is no cause for concern (Omelicheva \& Avdeyeva, 2008, p. 604; Oros, 2007, p. 303). In short, smaller classes allow every student to participate in the class, albeit in different ways at different times.

The same is not true in larger lecture hall classes. Observers in a lecture hall likely outnumber participants several-fold (Hensley \& Oakley, 1998). For an example, see www.justiceharvard.com (35 minutes into Episode 3) for an example of this dynamic when Dr. Michael Sandel engages a team of students dubbed "Team Libertarian" in a debate in lecture hall of students. In this example, as in Omelicheva and Avdeyeva's (2008) work, most students are left observing the small minority of students chosen to engage in the debate. Logistically this precludes every student from speaking to the class because of the sheer time it will take. For example, Levy and Orr (2014) attempt to use debates in a large lecture class, but ultimately divide the 65 students in the experimental group (i.e. those conducting the debate) into smaller deliberation groups of roughly eight students to promote fuller student interaction rather than 
proceed with a sustained whole group debate. Thus, scaling up structured debates to the lecture hall and maintaining the active engagement of students requires that we rethink the prizefight metaphor.

\section{Alternative Metaphors}

Fortunately debate formats and goals can and do vary (Engel et al., 2017). Here we consider three variations. First, political primaries are a form of debate which often features multiple participants staking out moderate or extreme positions on the issues to win over voters (e.g., the 2016 Republican primaries). At their best, primary-style debates focus on framing arguments, exploring rhetoric, and clarifying basic beliefs and facts. As a second option, scholarly debates often involve diverse paradigmatic communities with diverse approaches to a topic arguing whether and how much a given study advances knowledge (Omelicheva, 2007). Fact-finding, theorizing, and knowledge building are the dominant goals for scholars. Thirdly, parliamentary debates showcase two (or more) competing ideologies, but are fundamentally votegetting and/or problem-solving endeavors (Sands \& Shelton, 2010). Notice that shifting metaphors modifies both the format and goals of a debate.

Ultimately the goals of the specific lesson should guide the choice of metaphor. We opted to frame the Waltz-Sagan debate over the dangers of nuclear proliferation as a primary-style debate. We did this to focus student attention on the spectrum of political positions possible as well as the rhetoric and evidence available regarding nuclear proliferation. Thus, students spent most of their time interrogating the arguments and evidence of the existing Waltz v. Sagan debate, rather than researching and advancing novel arguments.

\section{The Waltz v. Sagan Debate}

Amongst the general public, the argument that nuclear proliferation is dangerous is often taken as an assumed truth. Yet among scholars of nuclear politics the threat posed by nuclear proliferation is not nearly so self-evident. Building on his seminal work Theory of International Politics (1979), Waltz offers a robust defense of nuclear weapons and their proliferation as a "tremendous force for peace" (Waltz, 1981, 1990). For his work in the field nuclear politics specifically, Waltz received the Heinz Eulau Award in 1991 for the Best Article in the American Political Science Review in 1990 - "Nuclear Myths and Political Realities." Waltz's argument for pacifying effects of nuclear proliferation stretches across several articles and a series of live debates, as well as a book co-authored with his frequent debating opponent Scott Sagan (Sagan et al., 2007; Sagan \& Waltz, 2012; Waltz, 1981, 1993, 2012).

Across those diverse forums, Waltz's reasoning precedes along two lines of argument. In the first, he explores in great depth the logical requirements of deterrence - capability vs. credibility of action and the certainty of outcomes. Waltz examines how these aspects of deterrence function to reduce the likelihood of conflict where one state fears invasion. For example, Waltz argues that the second-strike capacity allows for the destruction of whole cities and populations, even after a state suffers a successful invasion or nuclear attack (e.g., Pakistan, North Korea). Waltz contends that this capacity makes miscalculation difficult and bars leaders from contemplating "winning" a war with a smaller, weaker nuclear state (Sagan \& Waltz, 2012, p. 44; Waltz, 1990, p. 744).

In his second line of argument, Waltz uses both thought experiments and historical examples to demonstrate how the possession of nuclear weapons affects the core logic of realism, i.e., balancing power. Waltz also produces a policy recommendation from this analysis about the "folly of maintaining more nuclear weapons than deterrence requires" (Waltz 1990, 741). In doing so, Waltz charges his debate opponents with adopting an American-centric position. He argues that for small states seeking to balance the power and limit the threats of large aggressive states - like the US - it makes perfect sense to pursue nuclear weapons.

Historically, he points out that nuclear weapons have rarely been used offensively or even for blackmail. And the examples of proliferation that we can observe (e.g., Pakistan, India, Iran, and North Korea) show a pace of proliferation which Waltz rightly refers to as glacial. Moreover the states that have acquired nuclear weapons have done so to protect their core national interests (Sagan \& Waltz, 2012, p. 
19). At its logical extreme, Waltz's position imagines a future world in which many countries acquire nuclear weapons and exist in an uneasy though peaceful state of mutual deterrence (Waltz, 1990, p. 744).

Sagan emerged as Waltz's most frequent debate opponent over a series of articles (Sagan, 1990, 1994, 1995, 1996, 2011). In these articles Sagan makes the case for the dangers of nuclear weapons, especially their proliferation to unstable states. For his work on nuclear politics, Sagan received both the International Studies Association's 2017 Susan Strange Award for challenging conventional wisdom and organizational complacency, and the National Academy of the Sciences 2015 Estes Award.

Sagan focuses on the operational realities of the political and military organizations that control nuclear weapons. To counter Waltz's "nuclear optimism" about the survival rationality forced upon leaders with nuclear weapons, Sagan lays out evidence that military organizations - because their "common biases, inflexible routines, and parochial interests - display organizational behaviors that are likely to lead to deterrence failures and deliberate or accidental war" (Sagan \& Waltz, 2012, p. 47).

Sagan pairs this shift in the level of analysis with a rich historical account of near misses (nuclear nonevents), putting forward example after example of timely interventions, organizational failings, lucky accidents, and fortunate delays that are behind the rare use of nuclear weapons that Waltz cites. To this reading of history Sagan adds contemporary evidence that "future nuclear-armed states will lack the positive mechanisms of civilian control," which more-developed nuclear states possessed when the developed weapons and still possess (Sagan \& Waltz, 2012, p. 48). Thus, Sagan's line of argument concludes, the probability of nuclear exchange is not zero as nuclear optimists suggest. Rather, as number of nuclear states rises, so too will probability of a nuclear event, whether intended or accidental.

\section{Designing the Debate: Goals, Structure, and Feedback Mechanisms}

In the Introduction to IR course, we designed a primary-style debate with an emphasis on establishing the arguments of each position. Given that this was an introductory class we wanted students explore both the arguments and the evidence Waltz and Sagan marshalled. Unlike prizefight debates during which students are expected to become positional experts through research (Oros, 2007), our students were tasked with sifting through the rhetoric of the Waltz-Sagan debate, determining which arguments were wellreasoned or not and acquiring familiarity with basic facts of nuclear proliferation. Other pedagogical goals besides winning a debate might include gaining familiarity with a political process, exploring a broad diversity of views, or constructing a policy compromise.

We announced the debate in the two weeks leading up to it and we designed the debate environment to prioritized persuasion in three ways. First, we used the lecture hall space to physically represent the different positions. 
FIGURE 1

CLASSROOM WHERE THE DEBATE WAS HELD

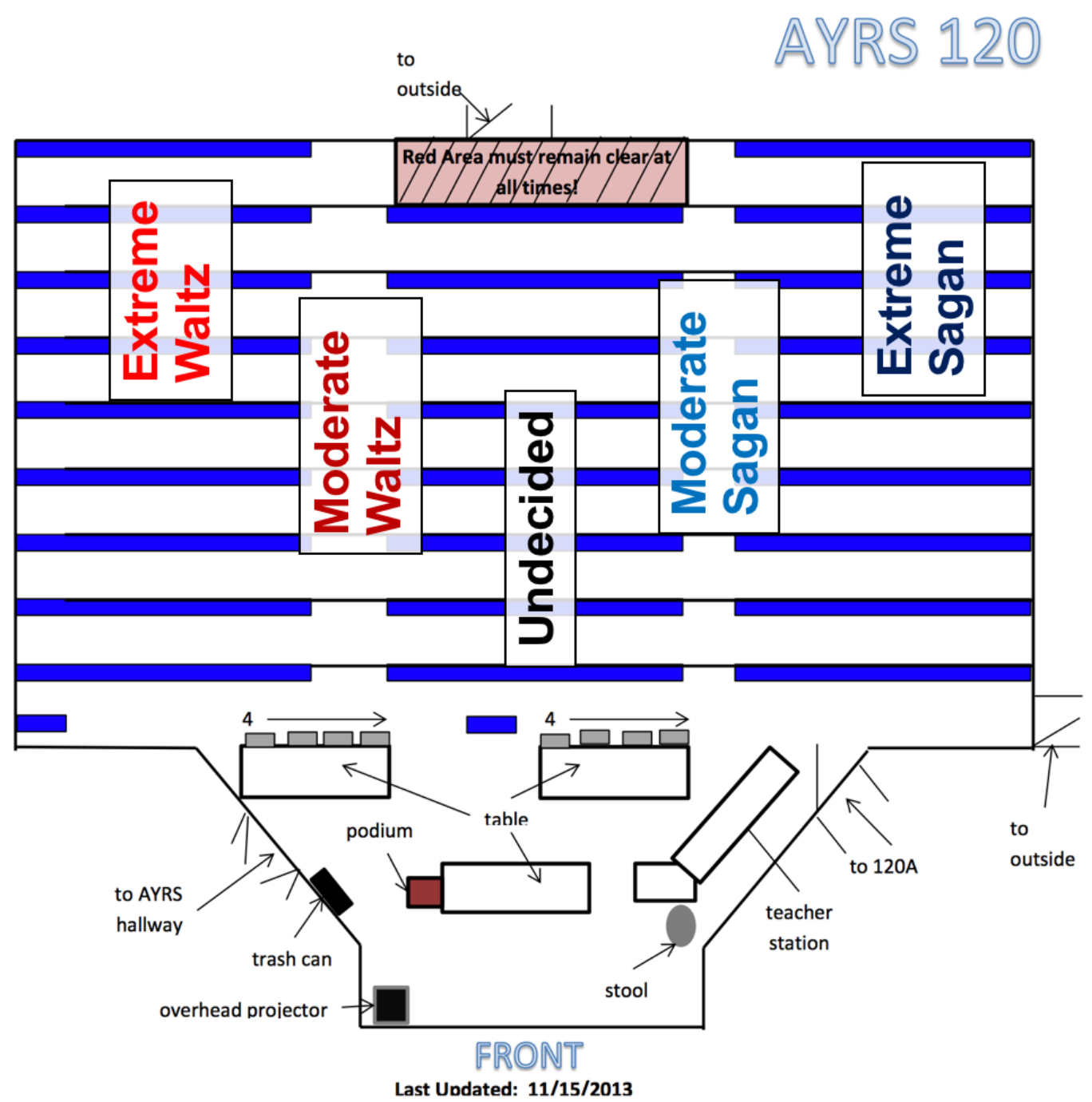

158 fixed tiered

seating- blue

8 ACR

chairs

Capacity: 166

As they entered the classroom, students chose to sit in one of five groups based on their initial position. Arranged from left to right, we divided the stadium seating into: Extreme Waltz, Moderate Waltz, Undecided, Moderate Sagan, and Extreme Sagan. As the students entered the classroom, we emphasized that seat choice was not permanent. Students would be free to change their seats to the right or left in order to accurately reflect their current position.

Next, we briefly discussed the different positions in terms of "agreeing with" an author's position. During this discussion several students shifted their seats to reflect their starting position. For example, if a student found Waltz's arguments very compelling and she had little to no doubt as to the accuracy of Waltz's analysis, then she would likely sit in the extreme Waltz section. However, if she held one or more serious reservations, she would sit with the moderate Waltz area. By physically grouping students we hoped to create a loose team dynamic for the argument and rebuttal formulation rounds of the debate. While formulating arguments, we did observe students forming pairs and small groups of three to four students. 
They did this primarily with students seated nearby in order to discuss what arguments they believed might sway classmates to their position or defend their position from critiques.

The debate occurred in four 15-minute rounds: 1) formulating initial arguments, 2) delivering initial arguments, 3) formulating rebuttals, and 4) delivering rebuttals. Before, between delivering initial arguments and formulating rebuttals, and after the final round students could move seats to indicate a change in their positions. When students moved, it was common for their classmates to ask which arguments swayed them most. During each of the seat moving times, students were encouraged to record their position and arguments they found compelling on a single page "Debate Notes" handout that we provided (See Appendix A). Students who attended the debate submitted their debate notes to mark their attendance that day.

The next class period was split between a lecture summarizing the Waltz-Sagan debate and a debriefing the lecture hall debate. Three class sessions (roughly one and half weeks) later, students were offered an online, 10-question, multi-choice extra-credit quiz on the Waltz-Sagan debate (See Appendix B). The students were told in class and in text at the top of the quiz that extra credit would be awarded for simply completing the quiz, regardless of their score. Completing the quiz would increase an upcoming midterm score by one percentage point. The instructions notified them that they did not need to study or look up answers, but that they should make their best guess as to the correct answer for each question. In the end, a sizable majority of the class $(88 \%)$ opted to take the extra credit quiz.

\section{Student Learning From a Lecture Hall Debate: A Quantitative Look}

In Fall 2017 the debate over nuclear proliferation happened to overlap with the extracurricular commitments of many students (e.g., sporting competitions, club trips/events). Additionally, several students emailed us in advance requesting and excuse absence for illness due to a nasty flu that was working its way through the campus. As in many large universities, several weeks into the Fall semester we see a rise in student absenteeism due to the combination of colds being shared between students living in college dorms and the onset of flu season (CDC, 2017). As a result, only 81 of 117 students in the Introduction to IR class were able to attend the debate. We seized on this confluence of events as an opportunity for a natural experiment to analyze the effectiveness of the debate against the control of students who did not attend the debate. Comparing the first midterm grades of students who attended versus those that did not, we find no statistically significant difference in their scores. The first midterm was held before the debate; thus, it serves as a rough proxy for prior student effort and aptitude in studying IR topics. According to class attendance records, the review and debrief class following the debate was attended by all the students that were absent during the debate. In that class we reviewed the debate and then debriefed what happened during the classroom debate. Thus, every student either participated in the debate and was present to hear the debate summary and debrief, or they watched the debate online and attended the summary debrief class.

Three class meetings (roughly one and a half weeks) after the whole class debrief, we offered the extra credit quiz on the course website. We reasoned that this amount of time would ensure that we were assessing longer term memory of the debate, rather than offering a quiz directly after the experience. This quiz featured ten multi-choice questions about both the facts and the positions of authors engaged in the debate. Out of 117 students, 103 students took extra credit quiz. The extra credit was offered for simply completing the quiz and we purposefully instructed the students that they "did not need to review or study for the quiz but should try to select the answers they thought were correct." The students that participated in the debate and the review/debrief lecture averaged 6.4 correct responses on the quiz $(S D=1.9)$. In contrast, the students that were absent from the debate and only experienced the review/debrief lecture averaged 4.7 correct responses on the quiz $(S D=2.3)$. After testing for skewedness, kurtosis, and unequal variances the debate quiz scored for each group were normally distributed and Levene's test did not reveal unequal variances between the two groups - we conducted an independent samples t-test which revealed that these numerically difference in debate scores was statistically significant, $t(101)=-3.75, p=0.0001$. This result suggests that participating in the debate may have improved students' recall several days later by nearly two correct responses out of ten questions. 
There is an alternative explanation that it was just more exposure to the debate and topic (i.e., students attending simply did more with the material). While this is possible, we suspect that engaging directly with the debate, not simply spending more time with it, resulted in the improved average score. All students were most recently exposed to a lecture discussion of the debate and yet a week and a half later students that were only exposed to that lecture and the video of the debate did worse on a recall quiz. While we cannot say that the debate necessarily outperformed other alternatives, it clearly did add more to student understanding than video watching and lecture review.

Next, we examined constructed control variables of likely alternative explanations. Using information from the introductory class survey of students, we coded each student's standing and major, as well as the number and type of positions taking during the debate. To assess the different progress of students we incorporated measures of a student's progress in their college career (year $=1-4$, senior $=4$ ), whether they were a non-IR, non-political science major, political science major, or IR major (major $=0-2$, IR major=2). We also examined gender (female $=1$ ), and their prior performance in the class in the first midterm exam (midterm grade $=0-100)$. From the debate itself, we included a measure of participation (participated $=1$ ), whether students changed position once, twice, or not at all (position change $=0-2$ ), as well as their final position (Waltz $=1$ ).

We then used OLS regression to determine the effect of debate participation in the context of these other factors.

\section{TABLE 1}

\section{COEFFICIENT ESTIMATES FOR DEBATE QUIZ SCORE}

\begin{tabular}{|c|c|c|c|c|}
\hline Variable & Model 1 & Model 2 & Model 3 & Model 4 \\
\hline Debate Participation & $\begin{array}{l}1.70 * * * * \\
(0.45)\end{array}$ & $\begin{array}{l}1.64 * * * * \\
(0.45)\end{array}$ & $\begin{array}{l}1.92 * * * * \\
(0.50)\end{array}$ & $\begin{array}{l}1.69 * * * * \\
(0.44)\end{array}$ \\
\hline Major & & $\begin{array}{l}0.13 \\
(0.31)\end{array}$ & $\begin{array}{l}0.11 \\
(0.31)\end{array}$ & \\
\hline Year & & $\begin{array}{l}0.07 \\
(0.24)\end{array}$ & $\begin{array}{l}0.31 \\
(0.24)\end{array}$ & \\
\hline Gender & & $\begin{array}{l}0.83 * * \\
(0.42)\end{array}$ & $\begin{array}{l}0.79 * \\
(0.42)\end{array}$ & $\begin{array}{l}0.90 * * \\
(0.40)\end{array}$ \\
\hline Midterm Grade & & $\begin{array}{l}-0.02 \\
(0.03)\end{array}$ & $\begin{array}{l}-0.24 \\
(0.24)\end{array}$ & \\
\hline Position Changed & & & $\begin{array}{l}-0.25 \\
(0.25)\end{array}$ & \\
\hline Final Position & & & $\begin{array}{l}0.49^{*} \\
(0.25)\end{array}$ & $\begin{array}{l}0.44^{*} \\
(0.24)\end{array}$ \\
\hline
\end{tabular}

Note: Adj. $R^{2}=0.16$ (Model 4)

${ }^{*} p \leq .10 . * * p \leq 0.05 . * * * p \leq .01 . * * * * p \leq .001$

Corroborating the t-tests above, Table 1 shows that students who participated in the debate were more likely to earn higher marks on the follow up quiz than those who did not. These results suggest that attending class and participating in a large, freewheeling debate results in greater recall of key debate facts and positions as compared than self-study, a review lecture, and a debrief of the debate.

Table 1 also reveals two additional factors that affected student performance on the follow up exam: gender and their final position. Of the two, gender is the returns the most substantive and statistically significant results across our models, yielding nearly a point better performance on the quiz if a student was female. This result is somewhat surprising because gender does not reach statistical significance when regressed on either of the course midterms or final exams. Additionally, the nature of the activity - a large, boisterous debate - would seem to promote and reward aggressive, argumentative masculine behavior. Prior research into education and gender has identified such behavior as a source of disparities in classroom 
participation (Caspi et al., 2008). Though we did not track participation by gender during the debate or the review session. In both meetings many of the female students offered their thoughts, provided critiques of arguments, and asked questions. We conjecture that this may be linked to our decision to design both the debate and debrief toward understanding each side's arguments rather than determining a winning side. Further research would be needed to confirm this suspicion.

Lastly, students identifying with the "Waltz" position returned statistically significant better quiz scores than undecided or Sagan supporters. The student notes below suggest that this is likely due to the simple, direct nature of Waltz's arguments and how those arguments hang on two widely discussed term in IR: deterrence and mutually assured destruction. Although the Waltzian position appears to have resulted in better recall of these concepts, the effect was minor, only accounting for a half point increase on the follow up quiz.

Taken together these results suggest that debating in the lecture hall can accomplish more than just increased student excitement and engagement. Based on this study, adapting a debate to a lecture hall appears to aid student recall of key facts and positions in the debate above and beyond lecture and debriefing the debate. More broadly this would suggest that opportunities await those of teaching in large lecture halls if we open our classrooms to the messy, hurly-burly cacophony of student taking positions, discussing arguments, questioning reasoning, shifting positions, airing justifications, and offering rebuttals. Rather than try to recreate the tension of a scholarly debate ourselves, alone at the lectern, we may be better off turning that task over to the sea of faces in front of us.

These findings track with recent work in other fields like social psychology, which understand learning - moral, political, or otherwise - as navigating emotional (or intuitive) pushes and pulls of an argument by understanding and empathizing with others even before we apply reason to evidence (Haidt, 2013). As this study will show, even when confined to exploring existent arguments, a lecture hall-sized debate can cultivate an appreciation of each sides position, arguments, and even motivate student creativity.

\section{Student Position Taking and Arguments: A Qualitative Look}

At the start of the debate students were given a two-page handout to record their debate notes. They were instructed to record their initial, between rounds, and final positions as well as any arguments or supporting evidence the student found compelling. These debate notes vary in their composition from lengthy paragraphs and sentences to bullet points. At some point though nearly, every student offered several sentences or paragraphs on the handout to describe arguments about nuclear proliferation they found compelling. Prior to the start of the debate, students were encouraged to be creative, to draw up several arguments or justifications, as well as to consider what students sitting in other positions might argue. We reviewed these debate notes to examine both the positions that the students took and the different arguments they considered.

TABLE 2

STUDENT POSITIONS DURING THE DEBATE

\begin{tabular}{|l|c|c|c|}
\multicolumn{1}{c}{ Student Position } & Initial Selection & Between Rounds Selection & Final Selection \\
\hline Extreme Waltz & 3 & 8 & 11 \\
\hline EW/MW & 1 & 5 & 5 \\
\hline Moderate Waltz & 14 & 22 & 18 \\
\hline Undecided & 27 & 3 & 4 \\
\hline Moderate Sagan & 30 & 25 & 20 \\
\hline ES/MS & 2 & 5 & 8 \\
\hline Extreme Sagan & 4 & 8 & 9 \\
\hline Total & 81 & 76 & 75 \\
\hline
\end{tabular}


As Table 2 indicates over a fourth of students started out claiming they were "Undecided." While we cannot be sure of the reason why, there was clearly an initial reluctance to take a position. Regardless of the reason, this group eroded quickly entering the between rounds selection (after having heard the first round of argument, but before students started assembling rebuttal arguments for the second round). Notably students in both the Waltz and Sagan camps offered arguments and asked questioned clearly intended for the undecided students. Across the rounds there was movement between and within each camp. Out of 81 participating students, 38 students $(47 \%)$ moved at least one position space during the debate with 13 students $(15 \%)$ moving 2 or more spaces.

As shown above, changing position did not result in better performance on the quiz; however, the debate notes of the students who moved revealed an interesting phenomenon: students wanted to take positions inbetween the moderate and extreme camps (denoted above by EW/MW and ES/MS). From our interactions during the debate and our review of student notes, we surmise this desire to position themselves between categories existed for two reasons. First, several students wrote and mentioned following the debate that they did not want to be an "extremist" as a reason for taking an in-between position. Second, many students cited the concern that they could "see the arguments" of the other camp as reasons to resist taking an extreme position, even when their notes clearly imply a strong agreement with one side. Given these responses, we would caution others against using "Extreme" as a modifier when setting up a spectrum of available positions.

The debate notes of students contain one final piece of information: the different arguments that students recorded before, during, and after each round of debate.

TABLE 3

\section{FREQUENCY OF ARGUMENTS RECORDED BY DEBATE POSITION}

\begin{tabular}{|l|c|c|c|c|}
\multicolumn{1}{c}{ Student Position } & Deterrence & MAD & Human Error & Immorality \\
\hline Extreme Waltz & 10 & 9 & 4 & 1 \\
\hline EW/MW & 5 & 5 & 3 & 0 \\
\hline Moderate Waltz & 18 & 4 & 13 & 0 \\
\hline Undecided & 4 & 3 & 3 & 0 \\
\hline Moderate Sagan & 20 & 9 & 6 & 3 \\
\hline ES/MS & 3 & 0 & 8 & 6 \\
\hline Extreme Sagan & 6 & 3 & 50 & 19 \\
\hline Total & 66 & 33 & & \\
\hline
\end{tabular}

A simple count of the different types of arguments reveals what students in each position focused on. As expected, the major themes of Waltz (the logic of deterrence) and Sagan (human error) were the most heavily considered arguments accounting for $69 \%$ of the recorded arguments; with the mention of mutually assured destruction (MAD) occurring slightly more often amongst Waltz supporters (54\% of responses). The appearance of MAD as a compelling argument is interesting because of how rarely it is mention in the debate. As both Waltz and Sagan make clear, most emerging nuclear powers do not possess a capacity for assuring the destruction of an invading state because the possess far too few nuclear weapons. This concept was covered in a prior class on military strategies and its importation to the debate offers us a clue about how students are connecting different classes together - and possibly an opportunity to discuss the nuances of different terms.

Similarly, students imported several versions of ethically oriented immorality arguments. This is especially interesting because neither Waltz nor Sagan raises this concern either the video or text reviewed in advance of the class. In fact, both scholars confine their debate to the risks posed by nuclear proliferation, not the morality of possessing nuclear weapons. Yet, several students concentrated in the Sagan camp recorded and advanced ethical arguments about the immorality of nuclear weapons. Most reasoned that because nuclear weapons could destroy the world (or make portions of it unlivable) that the use and 
possession of nuclear weapons is fundamentally immoral. Regardless of its merits, this emergent argument demonstrated an opportunity to engage interdisciplinary discussion of morality and its role (or lack thereof) in international relations. If the class was confined to a lecture and review of the Waltz-Sagan debate as it unfolded on the video, it is doubtful this morality discussion would have come up.

\section{CONCLUSIONS}

Large lecture hall classes are unique educational experience. Often with fixed seating and an attentional focus on the stage and lectern, professors who find themselves in front of these large audiences must decide whether to hazard a discussion, let alone an activity. Any review interactive give and take that tries to involve most students is apt to gobble up substantial class time. Teaching in a large lecture hall can be a grinding experience for the instructor on the stage. The competing needs to inform, excite, inspire, and, at a minimum, keep students awake all placing unique demands on us as we step up to the lectern.

This study offers some consolation that same active learning techniques we practice in the seminar room can successfully be adapted to the lecture hall. In some cases, they may even outperform lecture with question and answer, the default strategy in most lecture halls. With minimal preparation and the use of basic feedback mechanisms (e.g., a handout), a properly adapted seminar techniques can focus the active learning clamor of the lecture hall to provide insight into student thoughts and experiences. Finally, this study demonstrates that in addition to enhancing student learning and engagement, adapting seminar techniques to the lecture hall can provoke serendipitous creativity on the part of students, adding to the class experience.

\section{REFERENCES}

Bain, K. (2004). What the Best College Teachers Do (1 edition). Harvard University Press.

Baumgartner, J.C., \& Morris, J.S. (2015). The "Crossfire Approach": Attracting Political Science Majors in Large-Lecture Sections of Introductory Courses. PS: Political Science \& Politics, 48(4), 612 616.

Bromley, P. (2013). Active learning strategies for diverse learning styles: Simulations are only one method. PS: Political Science \& Politics, 46(4), 818-822.

Caspi, A., Chajut, E., \& Saporta, K. (2008). Participation in class and in online discussions: Gender differences. Computers \& Education, 50(3), 718-724. https://doi.org/10.1016/j.compedu.2006.08.003

CDC. (2017, September 11). What You Should Know for the 2016-2017 Influenza Season. Centers for Disease Control and Prevention. Retrieved from https://www.cdc.gov/flu/about/season/fluseason-2016-2017.htm

Engel, S., Pallas, J., \& Lambert, S. (2017). Model United Nations and Deep Learning: Theoretical and Professional Learning. Journal of Political Science Education, 13(2), 171-184. https://doi.org/10.1080/15512169.2016.1250644

Farrelly, C. (2013). Play and Politics. Journal of Political Science Education, 9(4), 487-500. https://doi.org/10.1080/15512169.2013.835578

Haidt, J. (2013). The Righteous Mind: Why Good People Are Divided by Politics and Religion (Reprint edition). Vintage.

Hensley, T.R., \& Oakley, M. (1998). The Challenge of the Large Lecture Class: Making It More Like a Small Seminar. PS: Political Science and Politics, 31(1), 47-51. https://doi.org/10.2307/420433

Levy, D., \& Orr, S. (2014). Balancing the Books: Analyzing the Impact of a Federal Budget Deliberative Simulation on Student Learning and Opinion. Journal of Political Science Education, 10(1), 62 80. https://doi.org/10.1080/15512169.2013.859084

Omelicheva, M.Y. (2007). Resolved: Academic Debate Should Be a Part of Political Science Curricula. Journal of Political Science Education, 3(2), 161-175. https://doi.org/10.1080/15512160701338320 
Omelicheva, M.Y., \& Avdeyeva, O. (2008). Teaching with lecture or debate? Testing the effectiveness of traditional versus active learning methods of instruction. PS: Political Science \& Politics, 41(3), 603-607.

Oros, A.L. (2007). Let's Debate: Active Learning Encourages Student Participation and Critical Thinking. Journal of Political Science Education, 3(3), 293-311.

Raymond, C., \& Usherwood, S. (2013). Assessment in Simulations. Journal of Political Science Education, 9(2), 157-167. https://doi.org/10.1080/15512169.2013.770984

Rublee, M.R. (2007). Review of The Spread of Nuclear Weapons: A Debate Renewed. Journal of Political Science Education, 3(1), 105-106. https://doi.org/10.1080/15512160601126411

Sagan, S. (1990). Moving targets: Nuclear strategy and national security. Princeton University Press.

Sagan, S. (1994). The perils of proliferation: Organization theory, deterrence theory, and the spread of nuclear weapons. International Security, 18(4), 66-107.

Sagan, S. (1995). The limits of safety: Organizations, accidents, and nuclear weapons. Princeton University Press.

Sagan, S. (1996). Why do states build nuclear weapons? Three models in search of a bomb. International Security, 21(3), 97.

Sagan, S. (2011). The causes of nuclear weapons proliferation. Annual Review of Political Science, 14, 225-244.

Sagan, S., \& Waltz, K. (2012). The Spread of Nuclear Weapons: An Enduring Debate (3rd edition). W.W. Norton \& Company.

Sagan, S., Waltz, K., \& Betts, R. (2007). A Nuclear Iran: Promoting Security or Courting Disaster? Journal of International Affairs, 60(2), 135-150.

Sands, E.C., \& Shelton, A. (2010). Learning by Doing: A Simulation for Teaching How Congress Works. PS: Political Science \& Politics, 43(1), 133-138. https://doi.org/10.1017/S1049096510990690

Waltz, K. (1979). Theory of International Politics (1st edition). Waveland Press.

Waltz, K. (1981). The Spread of Nuclear Weapons: More May Be Better: Introduction.

Waltz, K. (1990). Nuclear Myths and Political Realities. The American Political Science Review, 84(3), 731-745. https://doi.org/10.2307/1962764

Waltz, K. (1993). The Emerging Structure of International Politics. International Security, 18(2), 44-79. https://doi.org/10.2307/2539097

Waltz, K. (2012). Why Iran should get the bomb: Nuclear balancing would mean stability. Foreign Aff., $91,2$. 


\section{APPENDIX A}

Debate Notes Handout (Two-sided)

Name:

Initial Position Chosen:

(Extreme Waltz; Moderate Waltz; Undecided; Moderate Sagan; Extreme Sagan)

Initial Arguments, Justifications, Questions on Waltz-Sagan Debate

[Space to respond]

Position Before Rebuttals:

(Extreme Waltz; Moderate Waltz; Undecided; Moderate Sagan; Extreme Sagan)

Did you change position? Yes No

(please explain why you did or did not change position)

[Space to respond]

Rebuttal Arguments, Justifications, Questions on Waltz-Sagan Debate

[Space to respond]

Final Position Chosen:

(Extreme Waltz; Moderate Waltz; Undecided; Moderate Sagan; Extreme Sagan)

Did you change position? Yes No

(please explain why you did or did not change position)

[Space to respond] 


\section{APPENDIX B}

\section{Waltz-Sagan Extra Credit Quiz}

This is an extra credit quiz that will be applied to your Midterm \#2 score. Prof. Irish is interested in determining how much of the debate you remember. You do not need to review your notes or re-watch the Waltz-Sagan Debate to prepare. Please answer with your best guess about the correct response. You will receive extra credit for completing the quiz regardless of your score.

Which scholar argues that the only way for developing states to protect themselves from larger nucleararmed rivals is by acquiring nuclear weapons of their own?

- Waltz, Sagan, Neither, Both

AQ Khan helped nuclear proliferation to other states. What state was his network based in?

- India, Israel, Iran, Pakistan

Do either Waltz or Sagan reject the claim that states are rational, unitary actors?

- Waltz, Sagan, Neither, Both

Ukraine spent millions of dollars to get rid of their nuclear weapons. Many years later parts of their country were invaded by Russia. According to this debate, with was likely due to a lack of

- Negotiation, Compellence, Deterrence, Organizational Theory

Which scholar cited multiple historical examples to reinforce his argument?

- Waltz, Sagan, Neither, Both

Which scholar believes that nuclear weapons are in large part responsible for the long-standing peace between the great powers since World War Two?

- Waltz, Sagan, Neither, Both

Which of the following states was NOT part of President Bush's "Axis of Evil”?

- Iraq, Iran, Syria, North Korea

Which scholar mentioned the role of gender in the attitudes of defense intellectuals toward nuclear weapons?

- Waltz, Sagan, Neither, Both

After World War Two, how many times have nuclear weapons been used in interstate wars?

- Never, Once, Twice, More than three times 